\title{
MERCADOS DE ANIMAIS: QUANDO OS NÃO-HUMANOS TORNAM-SE AMEAÇAS GLOBAIS
}

\author{
DANIEL BRAGA LOURENÇO ${ }^{1}$ \\ FÁBIO CORRÊA SOUZA DE OLIVEIRA ${ }^{2}$
}

RESUMO: As infecções zoonóticas sempre representaram um grave problema de saúde pública ao longo da história, acarretando danos irreversíveis ao bem-estar de seres humanos e à economia. A prática da criação, manejo e abate de animais para consumo humano no âmbito dos denominados mercados de animais tem sido a causa apontada para a mais recente pandemia da COVID-19 (Coronavírus Disease19). Impressiona a pouca atenção dada às reais causas desse cenário pandêmico, ainda mais diante de tão extensos e profundos efeitos negativos. O presente artigo pretende identificar na abusiva relação homem-animal a origem desse fenômeno. Mais que isso, apontar a origem animal da pandemia determina a necessidade de uma urgente revisão do estatuto moral dos não-humanos. Se isto não for feito, se práticas relacionadas ao consumo de animais não forem eliminadas, seremos provavelmente atingidos continuamente por problemas similares. A pandemia é uma questão de saúde pública, econômica, mas, sobretudo, moral.

Palavras-Chave: pandemia; COVID-19; infecções zoonóticas; animais nãohumanos.

\footnotetext{
1 Professor Adjunto de Biomedicina e de Direito Ambiental da Faculdade de Direito da Universidade Federal do Rio de Janeiro (UFRJ). Professor Titular de Direito Ambiental do Instituto Brasileiro de Mercado de Capitais (IBMEC). Professor do PPGD/UNIFG (BA). Professor da PósGraduação em Direito Ambiental Brasileiro da Pontifícia Universidade Católica do Rio de Janeiro (PUC/RJ). Doutor em Direito pela Universidade Estácio de Sá (UNESA/RJ). Mestre em Direito pela Universidade Gama Filho (UGF/RJ). Coordenador do Centro de Ética Ambiental/UFRJ. Coordenador do Antilaboratório de Direito Animal/UNIFG. Fellow do Oxford Center for Animal Ethics. CV:: http://lattes.cnpq.br/5869787995233483 ORCID: https://orcid.org/0000-0003-0807-439X Contato: daniel@lourenco.adv.br.

2 Professor de Direito Administrativo da Faculdade de Direito da Universidade Federal do Rio de Janeiro (UFRJ). Professor do PPGD/UNESA e Diretor do PPGD/UNIFG. Mestre e Doutor em Direito pela UERJ. Pesquisador Visitante (Estágio de Doutorando - CAPES) e Pós Lato Sensu na Faculdade de Direito da Universidade de Coimbra. Pós-Doutorado em Direito na UFSC (CNPQ). Coordenador do Laboratório de Pesquisa em Direito Administrativo/UFRJ e do Centro de Ética Ambiental/UFRJ. CV: http://lattes.cnpq.br/0708289449159110 Orcid: https://orcid.org/0000-00031694-5378 Contato: fabiooliveira@direito.ufrj.br.
} 
ABSTRACT: Zoonotic infections have always represented a serious public health issue throughout history, causing irreversible damage to the well-being of human beings and the economy. The practice of raising, managing and slaughtering animals for human consumption in the context of the so-called "wildlife markets" or "wet markets" has been the probable cause to the most recent pandemic of COVID-19 (Coronavirus Disease-19). The little attention paid to the real causes of this pandemic scenario is striking, especially in the face of the extensive and profound negative effects it produces. This article identifies the origin of this phenomenon in the abusive human-animal relationship. More than that, pointing out the animal origin of the pandemic determines the need for an urgent revision of the moral status of non-human animals. If this is not done properly, if animal-related practices are not effectively eliminated, we are likely to be continually affected by similar problems in the future. The pandemic is a public health issue as it is an economic one, but, above all, is a moral question we need to face.

KEYWORDS: pandemic; COVID-19; zoonotic infections; non-human animals.

\section{INTRODUÇÃO}

Conforme informa a Organização Mundial da Saúde (OMS - World Health Organization [WHO]), ${ }^{3}$ em 31 de dezembro de 2019 foi reportada, ao seu escritório na China, uma pneumonia de causa desconhecida detectada em Wuhan. Em 30 de janeiro de 2020, a OMS declarou Emergência de Saúde Pública de Interesse Internacional (Public Health Emergency of International Concern), que é o nível mais elevado de alarme emitido pela Organização. ${ }^{4} \mathrm{O}$ Brasil respondeu por meio da Lei no ${ }^{0} 13.979$, de 6 de fevereiro, que dispôs sobre "medidas para enfrentamento da emergência de saúde pública de importância internacional", a qual veio a ser, então, o marco normativo nacional de balizamento.

Em 11 de fevereiro de 2020, a Organização Mundial da Saúde divulgou o nome da doença ocasionada pelo novo coronavírus: COVID-19 (Coronavírus Disease-19), o número referenciando o ano da sua identificação. ${ }^{5}$ Já o coronavírus é chamado

3 Disponível em: https://www.who.int/emergencies/diseases/novel-coronavirus-2019/events-asthey-happen. Acesso em 30 out. 2020.

${ }^{4}$ Segundo noticia a OMS, neste momento havia 98 casos documentados e nenhuma morte em 18 países, além da China, do quais 4 (Estados Unidos, Alemanha, Japão e Vietnã) sinalizavam para a transmissão entre humanos. Também em janeiro de 2020, a China reconheceu a transmissão sustentada do vírus entre humanos e, assim, determinou quarentena em Wuhan e outras cidades da província de Hubei. Foi a primeira medida tomada de isolamento e de fechamento de áreas.

${ }^{5}$ Os coronavírus $(\mathrm{CoV})$ compõem um grupo catalogado na década de 60. São vírus que infectam humanos e animais e têm transmissão interespécies. Uma variante agressiva, então denominada 
SARS-CoV-2 (Severe Acute Respiratory Syndrome Coronavirus 2 ou Síndrome Respiratória Aguda Grave 2). Em 8 de março, a OMS acusou que 100 países registravam o vírus, com um total, computado na véspera, de 100.000 casos. Três dias depois, a World Health Organization declarou a COVID-19 como pandemia. ${ }^{6}$ Neste período, a Europa era o epicentro da pandemia, com alguns países seriamente atingidos, com ênfase para a Itália e a Espanha, e a OMS contabilizando 5.000 mortes. Na altura, a OMS recomendava enfaticamente a adoção de testes em massa para combate à transmissão. ${ }^{7}$

O contágio aumentava rapidamente (a transmissibilidade do vírus se mostrou alta) e o número de mortos crescia (embora a letalidade da doença não seja considerava elevada) ${ }^{8}$ No curso deste tempo, informações equivocadas e desencontradas circularam, como, por exemplo, a de que o uso de máscaras pela

Síndrome Respiratória Aguda Grave, a primeira, foi percebida em 2002, também na China. Nos anos seguintes a virose se espalhou pelo mundo.

6 "Speaking at the COVID-19 media briefing, the WHO Director-General said: 'WHO has been assessing this outbreak around the clock and we are deeply concerned both by the alarming levels of spread and severity, and by the alarming levels of inaction. We have therefore made the assessment that COVID-19 can be characterized as a pandemic. Pandemic is not a word to use lightly or carelessly. It is a word that, if misused, can cause unreasonable fear, or unjustified acceptance that the fight is over, leading to unnecessary suffering and death. Describing the situation as a pandemic does not change WHO's assessment of the threat posed by this virus. It doesn't change what WHO is doing, and it doesn't change what countries sould do. We have never before seen a pandemic sparked by a coronavirus. This is the first pandemic caused by a coronavirus. And we have never before seen a pandemic that can be controlled, at the same time.'"
Coronavirus
(COVID-19)
events
as they happen.
Disponível
em:

https://www.who.int/emergencies/diseases/novel-coronavirus-2019/events-as-they-happen.

Acesso em 11 de maio de 2020.

${ }^{7}$ Em seu comunicado: "Countries should test every suspected case of COVID-19. If people test positive, they should be isolated and the people they have been in close contact with up to 2 days before they developed symptoms should be sought out, and those people should be tested too if they show symptoms of COVID-19. WHO also advises that all confirmed cases, even mild cases, should be isolated in health facilities, to prevent transmission and provide adequate care. But we recognize that many countries have already exceeded their capacity to care for mild cases in dedicated health facilities. In that situation, countries should prioritize older patients and those with underlying conditions." Disponível em: https://www.who.int/emergencies/diseases/novelcoronavirus-2019/events-as-they-happen. Acesso em 30 out. 2020.

${ }^{8}$ Outros vírus e coronavírus apresentaram capacidade de transmissão menor e maior índice de letalidade. O MERS-CoV (Síndrome Respiratória do Oriente Médio), diagnosticado em humano em 2012 e com contaminação indicada a partir, por exemplo, de camelos e morcegos, teria potencialidade de transmissão mais baixa e fatalidade mais alta, estimada entre $30 \%$ e $40 \%$. Não houve uma pandemia da MERS-CoV. A SARS-CoV-1, também com menor condição de contaminação do que a SARS-CoV-2, teve a sua letalidade calculada entorno de $10 \%$. Em tese, mais baixa, portanto, que a MERS e superior a SARS-CoV-2, que teria percentual girando por volta de $4 \%$ ou $5 \%$. Todavia, existem estudos diversos, com metodologias diferentes, bem como pesquisas em curso, o que aponta para alguma variação destes dados. 
população não seria uma medida eficaz, tendo pertinência apenas para profissionais de saúde. Depois, como a própria OMS admitiu, tratou-se de um discurso estratégico a fim de não faltar, na época, tal equipamento para profissionais. ${ }^{9}$ A este conjunto extenso de notícias circulando se deu o nome de infodemic. ${ }^{10}$ Outros casos, como a transmissão em áreas abertas, pelo ar, o estado do vírus em superfícies, o uso de certas substâncias ou drogas para a prevenção e para o tratamento da doença, a possibilidade de reinfecção, comorbidades que potencializam o risco de fatalidade, o isolamento vertical, a resposta das crianças e jovens à infecção, revelam dissonâncias e dúvidas, o que é compreensível tendo em conta que a ciência está procurando entender o novo coronavírus na medida em que os fatos evoluem. ${ }^{11} \mathrm{~A}$ própria OMS registra o esforço científico inédito e em

\footnotetext{
${ }_{9}$ V., por ex., a fala de Tedros, Diretor-Geral da OMS no dia 7 de junho.

10 "'We're not just fighting a pandemic; we're fighting an infodemic,"” said Tedros Adhanom Ghebreyesus, WHO's director-general, at the 2020 Munich Security Conference. Fake news, misinformation, and conspiracy theories have become prevalent in the age of social media and have skyrocketed since the beginning of the COVID-19 pandemic. This situation is extremely concerning because it undermines trust in health institutions and programmes. On June 29, WHO formally began the conversation on the global effects and management of infodemics with its 1st Infodemiology Conference that convened international experts from diverse scientific and political backgrounds. Immediate and widespread sharing of medical and other scientific information outside of expert circles before it has been thoroughly vetted (eg, preprints) can be dangerous, especially in a pandemic. A pandemic is a rapidly evolving setting, in which researchers and medical professionals are constantly learning and contributing to dynamic adjustments in government policy. Compounding this information vortex is the fact that governments rarely make policy decisions solely on the basis of empirical evidence; political interest is key, and the two are frequently at odds." The Lancet, editorial, v. 20, ag. 2020. Disponível em: https://www.thelancet.com/journals/laninf/article/PIIS1473-3099(20)30565-X/fulltext. Acesso em 30 de out. 2020.

${ }^{11}$ Um caso dentre os mencionados, em comunicado de 15 de maio, a OMS: "Relatively few cases of infants confirmed to have COVID-19 have been reported; those who are infected have experienced mild illness. Recently, however, reports from Europe and North America have described clusters of children and adolescents requiring admission to intensive care units with a multisystem inflammatory condition with some features similar to those of Kawasaki disease and toxic shock syndrome. It is essential to characterize this syndrome and its risk factors, to understand causality, and describe treatment interventions. It is not yet clear the full spectrum of disease, and whether the geographical distribution in Europe and North America reflects a true pattern, or if the condition has simply not been recognized elsewhere." Disponível em: https://www.who.int/emergencies/diseases/novel-coronavirus-2019/events-as-they-happen Acesso em 30 out. 2020. Outro exemplo foi a associação feita entre o consumo de tabaco e a prevenção à COVID-19, o que a OMS rejeitou mais de uma vez. O emprego da hidroxicloroquina foi também debate famoso, defendido fervorosamente como de uso generalizado pelo presidente Donald Trump (EUA) e pelo presidente Bolsonaro, enquanto a OMS admitia administrar a substância tão somente em casos excepcionais tanto pela falta de comprovação acerca do seu benefício como pelos possíveis efeitos colaterais severos.
} 
rede, juntamente com outras ações, que alcançou resultados com brevidade recorde e que está concentrado em encontrar medicamento e vacina.

$\mathrm{O}$ enfrentamento à pandemia, em que pesem trabalhos em conjunto e o consenso da comunidade especializada, não foi sempre convergente, coeso ou solidário. ${ }^{12}$ A conduta da China e da OMS foram questionadas, especialmente, mas não apenas, pelos Estados Unidos. Após a Europa, os Estados Unidos da América se tornaram e epicentro - e é o país que reúne o maior número de infectados e de mortos - e também a Índia e o Brasil. O presidente americano utilizou constantemente a expressão vírus chinês e no início de julho anunciou a iniciativa de retirada formal do país da OMS. No final de setembro, computava-se 1 milhão pessoas mortas pela COVID-19 em todo o mundo, com 32 milhões de infectados em 188 países. ${ }^{13}$ Em 30 de outubro, quase 1 milhão e 200 mil mortos e mais de 45 milhões de infectados. ${ }^{14}$ Segundo levantamento realizado permanentemente pela Universidade Johns Hopkins, após os Estados Unidos, a Índia é o segundo país em número de infectados e na sequência vem o Brasil; mas, em número de mortos, o Brasil está na frente da Índia. Os dados brasileiros: quase 5 milhões e 500 mil infectados e quase 160 mil mortes.

Os impactos da pandemia, globais e nacionais, são conhecidos. Milhões de desempregados, diminuição expressiva da atividade comercial, fronteiras fechadas entre países, falências, colapso de sistemas hospitalares, colégios e universidades fechados em todo o mundo, restrição da circulação (externa e interna), isolamento social. Além disto, acusações de corrupção (superfaturamento, por ex.) foram ouvidas, inclusive com processamento judicial, em vários países, como Alemanha, Estados Unidos, Holanda e Brasil. E consequências derivadas: como o aumento da violência doméstica contra a mulher e contra crianças. Apontou-se o aumento da adoção e compra de animais com o intuito de companhia. As Olimpíadas, que

\footnotetext{
${ }_{12}$ Um exemplo foi a compra de equipamentos, como respiradores e máscaras, no mercado internacional, que mostrou uma disputa entre países, entidades públicas e privadas, inclusive com leilão por bens e cancelamento, por razões diversas (inclusive por pagamento a mais), de produtos já encomendados. Ato de presidente Trump impediu a 3M de exportar produtos médicos para outros países. Máscaras encomendadas pela Alemanha teriam sido impedidas de embarcar na Tailândia e remetidas para os Estados Unidos. Diante disto, o ministro do interior da Alemanha, Andreas Geisel, chamou o ato de "pirataria moderna". Reclamações vieram também, por ex., da França e do Brasil. 600 respiradores, produzidos na China, encomendados por Estados do Nordeste não puderam embarcar no aeroporto de Miami. Em nota, a Bahia informou que a operação foi cancelada unilateralmente pelo vendedor. A suspeita levantada é que a carga tenha sido comprada por valor mais alto. Disponível em https://www.dw.com/pt-br/eua-s\%C3\%A3oacusados-de-reter-itens-m\%C3\%A9dicos-destinados-a-outros-pa\%C3\%ADses/a-53014838.

Acesso em 30 out. 2020.
}

${ }^{13}$ Disponível em: https://www.bbc.com/portuguese/internacional-54339632. Acesso em 30 de out. 2020.

14 Fonte: Universidade Johns Hopkins (Baltimore, EUA). Disponível em: https://coronavirus.jhu.edu/map.html. Acesso em 30 out. 2020. 
seriam no Japão, foram canceladas, o que se deu também com inúmeros eventos esportivos, alguns voltando depois sem a presença do público ou com público reduzido. Analistas e a ONU anunciaram "danos econômicos sem precedentes" e o aumento da pobreza. ${ }^{15} \mathrm{~A}$ Organização Internacional do Trabalho também mapeou uma "crise sem precedentes".

Especialistas alertaram para o novo normal, com abertura e fechamento de setores e regiões variando de acordo com a elevação, estabilização e redução de casos da COVID-19. Em finais de outubro, a Alemanha e a França, v. g., após uma reabertura, anunciaram novas restrições diante do aumento da contaminação. Situação anormal que deve perdurar até o surgimento da vacina, de medicação eficaz ou da imunização de rebanho. A Universidade Federal do Rio de Janeiro suspendeu a maioria das atividades de ensino no início do período letivo e só as retomou, virtualmente, em agosto. As ferramentas digitais funcionam bem no ensino superior, mas não entre crianças. $\mathrm{O}$ turismo e o transporte aéreo foram seriamente atingidos. Assinalou-se, no que seria uma dimensão positiva do problema, como resultado da redução da atividade econômica, do consumo, a diminuição da poluição, mas, em contraposição, já se verificou a tormenta ambiental relativa ao destino da imensa quantidade de luvas e máscaras descartáveis, já encontradas em grande quantidade no mar. ${ }^{16}$

São notórias as graves consequências da SARS-CoV-2. Além da morte e de sequelas derivadas da COVID, efeitos nocivos nas finanças, na liberdade, no convívio, no trabalho. Manifestações psicológicas, depressão. Alguns retrataram os impactos da pandemia como manifestação do fracasso do capitalismo, outros como o momento de ajustes, outros como oportunidade para o avanço do socialismo. Alguns vaticinaram que a sociedade estará melhor enquanto outros afirmaram que estará pior ao fim desta época. Profecias históricas. É certo, contudo, que o Estado ganhou força ou foi demandado a atuar, a intervir, a fornecer prestações. O que impressiona é a pouca atenção dada à causa da pandemia, ainda mais diante de tão extensos e profundos efeitos negativos. O que desencadeou a pandemia? De onde ela veio? Ela é produto de um evento aleatório da natureza? Força maior? Um azar?

É preciso falar sobre a causa da pandemia. Sob pena inclusive de novas pandemias. Mas não apenas por isto.

\section{ANTECEDENTES DA PANDEMIA}

As infecções zoonóticas sempre representaram um grave problema de saúde pública ao longo da história. Não são uma novidade. Afetam continuamente todas as partes do planeta, acarretando danos irreversíveis no bem-estar de seres

\footnotetext{
${ }^{15}$ Disponível em: https://news.un.org/pt/story/2020/03/1708882. Acesso em 30 de out. 2020.

16 Por ex.: https://noticias.uol.com.br/ultimas-noticias/reuters/2020/03/12/mascaras-contracoronavirus-poluem-praias-e-trilhas-de-hong-kong.htm e https://oglobo.globo.com/rio/mascarasdescartaveis-comecam-poluir-orla-do-rio-acendem-alerta-1-24562807 Acessos em 30 de out. 2020.
} 
humanos e animais não humanos, especialmente aqueles que se encontram em situação de maior vulnerabilidade ambiental e social.

Muitas dessas infecções emergem e reemergem em diferentes períodos e através de métodos de transmissão bastante distintos. As principais razões epidemiológicas para essas doenças podem ser identificadas em mudanças ambientais/ ecológicas, na criação intensiva de animais para consumo, na caça e contato com animais selvagens, aumento dos meios de locomoção e viagens, entre tantos outros fatores, quase todos relacionados a ações promovidas diretamente pelo homem (Åsjö; Kruse, 2006).

Do ponto de vista terminológico, doenças primárias entre animais que podem ser transmitidas para seres humanos foram denominadas de antropozoonoses (do grego "anthropós" para designar homem; "zoo" equivalente a animal; e "nosos" significando doença), enquanto que as doenças transmissíveis de humanos para animais não humanos chamadas de zooantroponoses (HUBÁLEK, 2003). Existem várias outras classificações que levam em conta não somente esse sentido da contaminação, como também o ciclo do agente etiológico. Mais recentemente, adotou-se o termo zoonose para designar genericamente qualquer doença infecciosa naturalmente transmitida entre animais não humanos e o homem (WHO/FAO, 1959).

A maior parte das doenças infecciosas ocorrentes em seres humanos tem origem em animais não humanos, ou seja, são zoonoses. A reunião conjunta da OMS/FAO/OIE, realizada em Genebra em 2004, estabeleceu em relatório que a tendência, mantido o atual regime de exploração abusiva da natureza, é que essas doenças e pandemias emergentes teriam ocorrência cada vez mais frequente, previsão que se tem revelado, infelizmente, verdadeira. ${ }^{17}$

Normalmente essas infecções de origem zoonótica requerem a presença de um vetor intermediário responsável pela transmissão, como é o caso, por exemplo, de doenças transmitidas por insetos tais como carrapatos, mosquitos (e.g. dengue, febre amarela, malária, doença de Lyme, febre maculosa, entre tantas outras). A distribuição dessas doenças é usualmente determinada por uma rede complexa de fatores ambientais e sociais, como mencionado, quase todos de origem antrópica. As alterações climáticas, o avanço da fronteira agrícola sobre áreas florestadas e a excessiva urbanização são vetores que tipicamente potencializam o contato humano com os vetores centrais dessas doenças.

Existem situações envolvendo infecções zoonóticas que podem contaminar diretamente o homem e a partir de um caso original ("paciente zero") e que têm o potencial de serem transmitidas em progressão geométrica para outros indivíduos via contato físico (saliva, sangue, urina). Esses casos geralmente envolvem a proximidade entre seres humanos e animais infectados, silvestres ou domésticos. A partir daí, a cadeia de contaminação prossegue entre os seres humanos com resultados imprevisíveis. Alguns exemplos desse fenômeno podem ser úteis para

${ }_{17}$ Disponível em: https://www.oie.int/doc/ged/D5681.PDF. Acesso em 20 jul. 2020. 
a melhor compreensão dos mecanismos de contágio que envolvem o recente avanço da pandemia do coronavírus.

No século XIX, em várias regiões da África, em razão do fim do tráfico de pessoas escravizadas, intensificou-se o processo de exploração de recursos naturais com plantações de café, banana, cacau e látex. Esse avanço humano sobre áreas nativas, antes não exploradas, determinou o contato direto com animais silvestres, inclusive sob a forma de alimento:

\begin{abstract}
Além de testemunhas, eles [chimpanzés] viraram vítimas: caçadores adentravam a mata em busca de sua carne. Mortos, seus corpos eram destrincados pelos facões, e seus pedaços, ensacados pelos homens armados. A jornada desses caçadores terminava nos mercados dos vilarejos próximos. Retornavam ensanguentados pela caça. Manipulavam a carne ensanguentada dos chimpanzés nos mercados. Os consumidores levavam a carne para suas residências e também entravam em contato direto com seu sangue. Os africanos não sabiam da existência de um vírus presente nesses chimpanzés de Camarões e Gabão. (UJVARI, 2019, p. 10)
\end{abstract}

A doença nomeada como Síndrome da Imunodeficiência Adquirida (SIDA/AIDS) se disseminou de modo silencioso na região em razão de conflitos armados ocorridos no século $\mathrm{XX}$ e consequente aumento da caça. Os resultados das pesquisas demonstram que as áreas ocupadas por chimpanzés coincidem com áreas de contaminação do HIV-1 e indicam que esses animais são a fonte primária da doença em seres humanos (GAO; BAILES; ROBERTSON, et al., 1999). Os macacos mangabey de Guiné-Bissau, na extremidade oeste do continente, estão, da mesma forma, conectados à disseminação do tipo 2 do HIV (UJVARI, 2019, p. 12-13).

De outro lado, a domesticação de animais não humanos colaborou ativamente para a disseminação de novas doenças de que são exemplos a varíola e o sarampo. No sudeste asiático a domesticação de aves favoreceu o surgimento do contágio pelo vírus influenza tipo A. Durante as migrações as aves selvagens paravam em reservatórios de água que abasteciam as criações de galinhas e porcos e eliminavam o vírus nestes locais por meio das fezes. $O$ vírus então circulava entre esses animais sofrendo mutações e adaptações ao invadir novas espécies (UJVARI, 2019, p. 141). Na primeira metade do século $X X$ houve três grandes episódios pandêmicos associados ao vírus da influenza. A "febre espanhola", em 1918-1919 (H1N1) foi a mais devastadora delas, eliminando em torno de 50 milhões de pessoas:

Em 1918, a causa da influenza humana e seu link com a influenza aviária e suína eram ainda desconhecidos. Apesar das similaridades clínicas e epidemiológicas às pandemias de 1847 e 1889, e até mais antigas, muitos questionaram se uma doença tão 
explosivamente fatal poderia ser de fato associada à influeza. Essa questão não foi resolvida até os anos 30, quando vírus de linhagem próxima (H1N1) foram isolados, primeiro de porcos e logo depois de seres humanos. Estudos soro-epidemiológicos demonstraram a relação desses vírus à pandemia de 1918 (TAUBENGERGER; MORENS, 2006, p. 15).

Em 1951-1952 houve um surto da então denominada "febre asiática" (H1N2) e da "febre de Hong Kong" em 1968-1969 (H3N2) que tiveram repercussão menor, relacionadas a uma origem aviária. A mesma origem viral se manifesta posteriormente em 2002 com a gripe aviária do subtipo H5N1 na Ásia. São conhecidos 16 tipo de hemaglutinina (de H1 a H16) e 9 tipos de neuraminidase, molécula associada à hemaglutinina (N1 a N9). Essa cepa, H5, bem como a H7 e a $\mathrm{H}$, embora com baixo risco de contágio, possuem alto índice de letalidade: ${ }^{18}$

O vírus foi capaz de saltar das galinhas ao homem pela primeira vez. Causou gripes humanas severas em que um terço dos doentes morreu. Foram 18 casos originais de gripe com 6 mortes, todos habitantes de Hong Kong que trabalhavam no meio das aves. Eram criadores, tratadores, trabalhadores de mercados ou outros profissionais com contato próximo com aves e seus excrementos (UJVARI, 2019, p. 148).

Em 1976, no Sudão e Zaire, na Nigéria, houve o grave caso de contaminação pelo vírus causador do Ebola, febre hemorrágica extremamente agressiva e que vitimou milhares de pessoas. Em anos subsequentes vários outros surtos da doença ocorreram em outras regiões. As fontes prováveis do Ebola estão relacionadas à contaminação direta por morcegos ou por meio do manejo, abate e consumo de primatas. ${ }^{19}$

Mais recentemente, em 2009, uma nova síndrome respiratória matou $200 \mathrm{mil}$ pessoas no mundo em apenas um ano, a H1N1 2009 pdm, conhecida como "gripe suína". Porcos criados para consumo foram contaminados pelo vírus da influenza e o ambiente de confinamento desses animais propiciou condições ideais para a disseminação da doença. ${ }^{20}$ Os porcos são especialmente suscetíveis a seres hospedeiros intermediários do vírus, pois seu sistema respiratório possui receptores tanto para o vírus da influenza aviária quanto para o vírus suíno/humano. A alta densidade populacional nas fazendas de criação industrial associada à imunodepressão dos animais em razão do ambiente estressante e

\footnotetext{
${ }^{18}$ Sobre a gripe aviária, cf. https://www.cdc.gov/flu/avianflu. Acesso em: 20 jul. 2020.

19 Sobre o ebola, cf. https://www.nationalgeographic.com/magazine/2015/07/ebola-epidemicmedical-science-outbreak. Acesso em 20 jul. 2020.

20
} 
artificial facilitaram a combinação e a recombinação de diferentes cepas de influenza, perfazendo sistemas de alta patogenicidade (PAIM; ALONSO, 2020, p. 23-24).

Resta claro por meio dos exemplos acima elencados, dentre inúmeros outros possíveis, que as principais causas para a propagação de infecções zoonóticas, que podem assumir efeitos globais, graves e imprevisíveis, é antrópica e provém diretamente da relação abusiva do homem para com a natureza e os animais não humanos.

\section{A CAUSA INDICADA DO CORONAVÍRUS SARS-COV-2: MERCADOS DE ANIMAIS NA CHINA}

Apesar de algumas especulações em sentido contrário, ${ }^{21}$ a compreensão científica, amplamente majoritária, é a de que a SARS-CoV-2 surge ou alcança contaminação de humanos no ambiente de um mercado de animais na cidade de Wuhan, capital da província de Hubei, China. ${ }^{22}$ É, inclusive, o que aponta a Organização Mundial da Saúde. ${ }^{23}$ Tais mercados, denominados de mercados

${ }^{21}$ As especulações são basicamente duas com esteio em uma suposta fonte comum. A tese é a de que o novo coronavírus é produto de experimentação laboratorial e também se especula sobre a finalidade desta manipulação. Então, duas coisas podem ter acontecido: 1) o vírus foi liberado propositadamente pela China em razão de interesses econômicos ou por alguém (ou alguns) por propósitos desconhecidos ou 2) o vírus escapou acidentalmente do laboratório. Ou seja, dolo na primeira hipótese, culpa na segunda, ambas, contudo, levando à responsabilidade do Estado chinês no plano interno e internacional. Nada disto restou provado e os indícios direcionam para hipótese diversa, conforme exposto a seguir.

${ }_{22}$ Confira-se o documentário Por que é que o coronavírus - Covid-19 - apareceu na China?, Disponível em: https://www.youtube.com/watch?v=aKA3MkbKvI0 Também o documentário How wildlife trade is linked to coronavírus. Disponível em: https://www.youtube.com/watch?v=TPpoJGYlW54.

Em estudo científico, v. g.: angpeng Xiao, Junqiong Zhai, Yaoyu Feng, Niu Zhou, Xu Zhang, JieJian Zou, Na Li, Yaqiong Guo, Xiaobing Li, Xuejuan Shen, Zhipeng Zhang, Fanfan Shu, Wanyi H uang, Yu Li, Ziding Zhang, Rui-Ai Chen, Ya-Jiang Wu, Shi-Ming Peng, Mian Huang, WeiJun Xie, Qin-Hui Cai, Fang-Hui Hou, Yahong Liu, Wu Chen, Lihua Xiao, Yongyi Shen. Isolation and Characterization of 2019-nCoV-like Coronavirus from Malayan Pangolins. BioRxiv (The Preprint Server for Biology) 2020.02.17.951335. Disponível em: https://www.biorxiv.org/content/10.1101/2020.02.17.951335v1 Acesso em 4 out. 2020. Confira-se tb.: https://www.nationalgeographic.com/animals/2020/04/coronavirus-linked-to-chinese-wetmarkets/; $\quad$ https://www.cnnbrasil.com.br/internacional/2020/06/22/feira-anual-de-carne-decachorro-e-aberta-na-china-e-desagrada-ativistas; https:/noticias.r7.com/saude/china-precisacombater-consumo-de-animais-selvagens-diz-medico-13022020

${ }_{23}$ "The first human cases of COVID-19, the disease caused by the novel coronavirus causing COVID19, subsequently named SARS-CoV-2 were first reported by officials in Wuhan City, China, in December 2019. Retrospective investigations by Chinese authorities have identified human cases with onset of symptoms in early December 2019. While some of the earliest known cases had a link to a wholesale food market in Wuhan, some did not. Many of the initial patients were either 
molhados (wet markets), de mercados de animais silvestres (wildlife markets), mercados de carne (meat markets) ou de mercados de animais vivos, comercializam, como os nomes dizem, animais marinhos, silvestres (selvagens) e, inclusive, animais vivos, muitos, então, mortos na hora ao gosto do cliente.

Tais mercados, chocantes, são considerados timebombs para o surgimento de epidemias. ${ }^{24}$ Em expressão do consenso especializado, a Fundação Oswaldo Cruz (FIOCRUZ) publicou em seu site:

Tudo leva ao mercado de peixes e animais exóticos de Wuhan, já que grande parte dos primeiros infectados esteve no local. Segundo o Centro de Controle e Prevenção de Doenças da China, foram coletadas 33 amostras na zona oeste do mercado, principalmente onde ficam as barracas de animais selvagens, e 31 testaram positivo para o coronavírus. ${ }^{25}$

Aponta-se que estes mercados, notadamente no que se refere à comercialização de animais silvestres, tiveram origem durante a época da Grande Fome, entre 1958 e 1961 ou 1962, no contexto de políticas implementadas pelo governo da República Popular da China, de Mao Tse-tung, o plano quinquenal intitulado Grande Salto para Frente em um cenário de agricultura coletivizada, na qual os camponeses estavam reunidos em comunas agrícolas, denominadas comunas populares. ${ }^{26} \mathrm{O}$ comércio de animais selvagens, como crocodilo, urso, tartaruga, sapo, escorpião, pato, porco-espinho, pangolim, morcego, texugo, cobra, aves, coelho e hamster, goza de aceitação por grande parte do povo, constituindo parte de uma cultura

stall owners, market employees, or regular visitors to this market. Environmental samples taken from this market in December 2019 tested positive for SARS-CoV-2, further suggesting that the market in Wuhan City was the source of this outbreak or played a role in the initial amplification of the outbreak. The market was closed on 1 January 2020. SARS-CoV-2 was identified in early January and its genetic sequence shared publicly on 11-12 January. The full genetic sequence of SARS-CoV-2 from the early human cases and the sequences of many other virus isolated from human cases from China and all over the world since then show that SARS-CoV-2 has an ecological origin in bat populations. All available evidence to date suggests that the virus has a natural animal origin and is not a manipulated or constructed virus. Many researchers have been able to look at the genomic features of SARS-CoV-2 and have found that evidence does not support that SARS-CoV-2 is a laboratory construct. If it were a constructed virus, its genomic sequence would show a mix of known elements. This is not the case." Disponível em: https://www.who.int/docs/default-source/coronaviruse/situation-reports/20200423-sitrep-94covid-19.pdf. Acesso em 31 out. 2020.

${ }^{24}$ Veja-se, por ex., a reportagem da BBC Coronavirus: Putting the spotlight on the global wildlife trade. Disponível em: https://www.bbc.com/news/science-environment-52125309 Acesso em 6 de abr. 2020.

${ }^{25}$ Disponível em: https://portal.fiocruz.br/noticia/covid-19-que-virus-e-esse Acesso em 30 out. 2020.

${ }^{26}$ A respeito: A grande fome de Mao: a história da catástrofe mais devastadora da China - 1958-62, de Frank Dikötter. Tradução por Ana Maria Mandim. Rio de Janeiro, São Paulo: Record, 2017. 
gastronômica. Nestes lugares é possível adquirir, por exemplo, pé de urso, asa de morcego e barbatana de tubarão. ${ }^{27}$ Ao lado do consumo da carne de gatos e cães. Como aduzido, animais vivos são mantidos em exposição para serem mortos no local. Nada obstante, o surto, em 2002, da SARS-CoV, a partir de Guangzhou, China, já havia sido percebido como advindo da comercialização de animais silvestres. O consumo destes animais e o funcionamento destes mercados são permitidos, os quais reúnem muitos frequentadores, inclusive turistas em busca de carne exótica.

É consabido que animais podem ser portadores de zoonoses. E, no processo de captura e transporte para confinamento em tais mercados e em outros lugares, entram em contato entre si, inclusive animais de espécies diferentes. E com seres humanos. Muitas vezes estão machucados. E mantidos com fome e sede. Amofinados em pequenas gaiolas: uns por cima dos outros, gaiolas em cima de gaiolas. E muitas vezes são mortos no local, na hora, esfolados, têm seus corpos abertos e despedaçados. As partes não vendidas, os dejetos, são comumente deixados no próprio lugar. Reportagens, fotos e vídeos facilmente disponíveis mostram tais ações. ${ }^{28}$ Acrescente-se, ademais, que mercados do gênero não existem apenas na China, estão espalhados pelo mundo: Indonésia, Tailândia, Cambodia, Filipinas, Vietnã e Índia, entre outros, inclusive com variações em países ocidentais, como Estados Unidos e Brasil..$^{29}$

Após a eclosão do novo coronavírus, mercados foram fechados, inclusive em Wuhan, ${ }^{30}$ mas algum tempo após voltaram a funcionar. ${ }^{31}$ Há um apelo popular, na

${ }^{27}$ Sobre a grotesca prática do finning, que, além do sofrimento e da morte do animal (afogado), tem drásticas consequências ecossistêmicas, o documentário Sharkwater.

${ }^{28}$ Disponível em: https://super.abril.com.br/sociedade/o-que-sao-os-mercados-chineses-de-animaissilvestres/;https://www.bbc.com/news/science-environment-52125309;

https://www.nationalgeographic.com/animals/2020/04/coronavirus-linked-to-chinese-wetmarkets/; https://www.theguardian.com/global-development/2020/apr/16/what-is-a-wet-marketcoronavirus. Acessos em 11 de maio de 2020. Vídeos: https://www.youtube.com/watch?v=aRflNSXVzX4; https://www.youtube.com/watch?v=0V7fyjaFOwQ;

29 Três vídeos da PETA (People for the Ethical Treatment of Animals): https://www.youtube.com/watch?v=sHBBOcHXojI; https://www.youtube.com/watch?v=UA21iCYsSDQ; https://www.youtube.com/watch?v=MkrPewCQHY\&feature=emb_logo. Nos Unidos: https://www.youtube.com/watch?v=kM11_voE6WU.

${ }^{30} \mathrm{https} / / / \mathrm{www}$.businessinsider.com/wuhan-china-bans-eating-wild-animals-2020-5. Acesso em 30 out. 2020.

${ }^{31} \mathrm{Na}$ reportagem Will they ever learn? Chinese markets are still selling bats and slaughtering rabbits on bloodsoaked floors as Beijing celebrates 'victory' over the coronavirus, do Mail Online: “Terrified dogs and cats crammed into rusty cages. Bats and scorpions offered for sale as traditional medicine. Rabbits and ducks slaughtered and skinned side by side on a stone floor covered with blood, filth, and animal remains. Those were the deeply troubling scenes yesterday as China celebrated its 'victory' over the coronavirus by reopening squalid meat markets of the type that started the pandemic three 
própria China, pelo fim do comércio de animais selvagens, amplificado pelo advento do novo coronavírus. ${ }^{32}$ Indica-se uma tendência de crítica e marginalização de tal atividade, com algum respaldo, vacilante, pelo Estado.

Vale registrar que os maus-tratos aos animais não estão circunscritos aos aludidos mercados. Variadas atividades implicam no sofrimento e na morte de animais, na sua coisificação, como em $\operatorname{circos}^{33}$ e na criação, aprisionamento e imobilização de ursos para a extração da bile, prática afeita à medicina popular chinesa. A extração da bile veio ser estimulada pela Comissão Nacional de Saúde da China que listou a substância para tratamento da COVID-19. ${ }^{34}$ Em 22 de junho

months ago, with no apparent attempt to raise hygiene standards to prevent a future outbreak. (...) Here cages of different species were piled on top of each other. In another meat market in Dongguan, southern China, another correspondent photographed a medicine seller returning to business on Thursday with a billboard advertising bats - thought to be the cause of the initial Wuhan outbreak - along with scorpions and other creatures.The shocking scenes came as China finally lifted a weekslong nationwide lockdown and encouraged people to go back to normal daily life to boost the flagging economy. Official statistics indicated there were virtually no new infections. The market in Guilin was packed with shoppers yesterday, with fresh dog and cat meat on offer, a traditional 'warming' winter dish. (...) The correspondent who visited Dongguan said: 'The markets have gone back to operating in exactly the same way as they did before coronavirus. The only difference is that security guards try to stop anyone taking pictures which would never have happened before."' Disponível em: https://www.dailymail.co.uk/news/article-8163761/Chinese-markets-sellingbats.html?ito=social-twitter_mailonline Acesso em 31 out. 2020. Tb., por ex.: https://revistaforum.com.br/coronavirus/china-reabre-mercados-que-voltam-a-vender-animaisvivos/; $\quad$ https://noticias.uol.com.br/internacional/ultimas-noticias/2020/05/16/video-de-ongmostra-que-mercados-de-animais-vivos-foram-reabertos-na-china.htm. Acessos em 31 out. 2020.

${ }_{32}$ Disponível em: https://www.nationalgeographic.com/animals/2020/01/china-bans-wildlife-tradeafter-coronavirus-outbreak/. Acesso em 30 out. 2020.

33 Para uma reportagem a respeito, entre tantas outras, a investigação Investigation Documents Animal Suffering at Chinese Circuses. Tigers, monkeys, and bears are the victims of a country without animal welfare laws, da National Geographic. Disponível em https://www.nationalgeographic.com/news/2016/07/wildlife-china-circus-animal-abuse/.

Acesso em 30 out. 2020.

34 “Em fazendas de ursos na China e no sudeste da Ásia, a bile utilizada na medicina tradicional é extraída pela inserção de um cateter, seringa ou tubo na vesícula biliar dos animais - um processo invasivo e doloroso. (...) Secretada pelo fígado e armazenada na vesícula biliar, a bile de várias espécies de ursos, incluindo ursos-negros-asiáticos e ursos-pardos, tem sido usada na medicina tradicional chinesa desde pelo menos o século 8. (...) Embora o uso de bile de ursos criados em cativeiro seja legalizado na China, a bile de ursos selvagens é proibida, assim como a importação de bile de urso de outros países. De acordo com Aron White, ativista dos direitos dos animais silvestres na Agência de Investigação Ambiental (EIA) - uma organização sem fins lucrativos sediada em Londres, na Inglaterra, que expõe crimes contra a vida selvagem -, sua organização ficou sabendo das recomendações do governo chinês sobre o tratamento da Covid-19 por meio de publicações de comerciantes ilegais nas redes sociais. 'Percebemos como a recomendação do governo estava sendo utilizada pelos contrabandistas para anunciar seus produtos ilegais como tratamento', afirma White. Bile de ursos selvagens é produzida ilegalmente 
foi aberto um grande festival anual de carne de cachorro, na cidade de Yulin. Os sobreditos mercados, como anotado, estão abertos.

Quanto ao agente transmissor direto não há posição consensual conclusiva. ${ }^{35} \mathrm{~A}$ transmissão para humanos pode ter se dado diretamente de morcego ou, por meio de um hospedeiro, como o pangolim. A OMS, assumindo que a fonte mais provável é o morcego, sugere que houve um intermediário entre ele e o humano. ${ }^{36}$

Uma vez que se reconhece que a pandemia foi desencadeada pelo comércio de animais silvestres, exercido destacadamente nos referidos mercados, três constatações são surpreendentes: 1) que a identificação da causa da SARS-CoV-2 não tenha ganhado o devido espaço na grande mídia e nem nos organismos internacionais, a exemplo da OMS, e tampouco a partir dos Estados Nacionais; 2) que não tenha havido, nesta mesma abrangência, pela iniciativa dos atores citados, um movimento articulado e forte de pressão sobre a China (e outros países) para o encerramento desta prática e de tais mercados; 3 ) que, apesar de todos os severos efeitos da COVID-19, a captura, a criação e a comercialização de animais silvestres sigam ocorrendo, bem como que os nefastos mercados estejam em funcionamento.

Gera também aturdimento verificar como o debate acerca da crueldade à qual os animais são submetidos, dos maus-tratos, da exploração, da coisificação destes seres não tenha se alastrado e gerado um acordo firme contra esta ignomínia. Os

na China, diz ele, e também é importada do Laos, Vietnã e Coréia do Norte de ursos selvagens e ursos em cativeiro. O comércio ilegal persiste, embora os ursos-negros asiáticos, uma das espécies mais cultivadas para extração da bile, sejam protegidos do comércio internacional pela Convenção sobre o Comércio Internacional de Espécies da Flora e Fauna Selvagens Ameaçadas de Extinção, que regulamenta o comércio transfronteiriço de animais silvestres e produtos provenientes desses animais. (...) Nas fazendas de extração de bile de urso na China e no sudeste da Ásia, os animais podem ser mantidos por décadas em pequenas gaiolas. A bile é rotineiramente extraída inserindose um cateter, seringa ou tubo na vesícula biliar. Todos os métodos para extrair bile são invasivos e 'causam sofrimento, dor e infecções', de acordo com a Animals Asia, uma organização sem fins lucrativos dedicada ao fim da criação de ursos para extração da bile. Negligência e doenças são comuns nessas fazendas e os consumidores correm o risco de ingerir bile de ursos doentes, que pode estar contaminada com sangue, fezes, pus, urina e bactérias, de acordo com a Animals Asia." https://www.nationalgeographicbrasil.com/ciencia/2020/04/china-uso-bile-de-urso-tratamentonovo-coronavirus-covid-19-oms. Acesso em 30 out. 2020.

${ }^{35}$ LI X, Zai J, Zhao Q, et al. Evolutionary history, potential intermediate animal host, and crossspecies analyses of SARS-CoV-2. J Med Virol. 2020; 92:602-611; ANDERSEN, K.G., RAUMBAUT, A., LIPKIN, W.I. et al. The proximal origin of SARS-CoV-2. Nat Med 26, 450-452 (2020); CYRANOSKI, David. Mysterydeepensoveranimalsounce of corronavirus.Pangolins are a prime suspect, but a slew of genetic analyses has yet to find conclusive proof. In: https://www.nature.com/articles/d41586-020-00548w? fbclid=IwAR1TaU8leMGzeMUzV0uZVIOBskJC2Zh4P7hixJfBEvwnsouHZGZnF4QTz_A Tb.: https://www.nytimes.com/2020/03/26/science/pangolin-coronavirus.html?smid=twnytimesscience\&smtyp=cur. Acesso em 4 jul. 2020.

36 Disponível em: https://www.who.int/docs/default-source/coronaviruse/situationreports/20200423-sitrep-94-covid-19.pdf. Acesso em 31 out. 2020. 
animais, presos, mortos, esfolados, degolados, com seus corpos retalhados, seu sangue escorrendo pelo chão enquanto os homo sapiens caminham à procura da carne a comprar, permanecem invisibilizados. A pandemia não vem do acaso. A pandemia vem da barbárie.

\section{A VACINA OFERECIDA PELA ÉTICA ANIMAL}

O pensamento ocidental caracteriza-se por demarcar grandes oposições entre as quais pode-se citar: natureza e cultura; natural e artificial; corpo e alma; primitivo e civilização; razão e emoção; humano e animal. ${ }^{37}$ Pode-se afirmar que em relação a estes últimos, esse modelo de visão de mundo dualista passou sistematicamente a corroborar a pré-compreensão no sentido de que os animais representariam uma condição de falta, de ausência, quando comparados à humanidade. ${ }^{38}$

É curioso perceber que existe hoje um senso comum relacionado ao fato de que a humanidade encontra-se inafastavelmente inserida na dimensão biológica da animalidade, afinal não há dúvida alguma sobre o fato de que a espécie Homo sapiens integra o reino animal, noção segundo a qual todos os animais são singulares e os homens são apenas mais uma espécie dentre tantas outras. De outro lado, a condição animal revela uma fronteira praticamente intransponível que separa essas duas categorias. Os animais não humanos representariam, como condição, aquilo que justamente se contrapõe ao fenômeno humano (condição humana), todo um enorme bloco de seres que estão excluídos, por ausência de singularidade, do padrão considerado relevante para ingresso na subjetividade moral e jurídica. Esse sistema de exclusão funciona como uma espécie de espelho negativo da experiência humana de mundo.

A cultura, neste sentido, sublinha a exclusividade da participação do homem na condição humana, tornando-o um sujeito (agente) moral, uma pessoa, um alguém, e não algo. Será um ente que possui dignidade existencial própria, imanente, fato que lhe concede imediato e automático acesso a uma vasta gama de direitos fundamentais. A animalidade, por sua vez, ficará tradicionalmente conectada apenas e tão somente ao mundo instrumental. Normalmente essa posição que confere estatuto moral próprio ao homem e, paralelamente, nega esta atribuição aos animais, está conectada ao fenômeno do antropocentrismo moral, que significa justamente afirmar que o mundo não humano possui valor somente na medida em que atenda, direta ou indiretamente, a interesses, preferências, necessidades, utilidades ou conveniências humanas (mundo não humano atrelado a valor relacional).

37 O pensamento pós-moderno critica e relativiza certas dualidades. É o que faz o paradigma da complexidade, de Edgar Morin. De Morin, a coleção O método, em 6 volumes, editada no Brasil. Também o livro Introdução ao pensamento complexo, igualmente publicado no Brasil.

38 Esse tópico acerca da consideração moral dos animais não humanos foi anteriormente desenvolvido com maior profundidade em LOURENÇO, 2018. 
A discriminação prejudicial injustificada em relação a seres não pertencentes à espécie humana configura o denominado "especismo" (speciecism), termo originariamente cunhado por Richard Ryder, psicólogo e professor da Universidade de Oxford, no artigo intitulado Experiments on Animals, datado de 1970, e posteriormente publicado como parte do livro Animals Men and Morals (GODLOVITCH, 1971). O neologismo designa uma forma de injustiça que significa tratamento diferenciado e prejudicial para aqueles que não integram a mesma espécie.

O especismo pode ser baseado no mero fato biológico do pertencimento de espécie (animais podem ser tratados de maneira prejudicial por não participarem da espécie humana) ou pode estar associado à defesa de que determinadas espécies possuem alguns atributos ou capacidades que justificariam esse tratamento privilegiado:

é justificável tratar desfavoravelmente aqueles que não possuem um atributo $X$ em relação aos que possuem este mesmo atributo $X$, onde a posse de $X$ é satisfeita somente por seres humanos e por todos os seres humanos (HORTA, 2014, p. 142).

Discriminar desfavoravelmente outras espécies seria justificável a partir da noção de que os seres humanos possuem determinados atributos que justificam seu tratamento privilegiado. Essa noção é muito disseminada. Vários autores e pensadores sustentam a primazia do humano, em contraposição à animalidade com base na ideia segundo a qual seres humanos possuem capacidade cognitivas especiais (tais como a razão, linguagem, pensamento abstrato, planejamento de futuro, capacidade de elaborar juízos morais, etc.); são capazes de manter relações especiais (sociais, afetivas, culturais, etc.) entre outras.

Todavia, conforme assinala a definição de Horta, acima apontada, para que a proposição do excepcionalismo humano funcione, ela deveria cumprir rigorosamente três grandes requisitos: (a) as características apontadas como justificadoras da especialidade humana frente às demais criaturas deveriam estar presentes em todos os seres humanos; (b) somente os seres humanos deveriam possui-las; e (c) tais atributos deveriam ser moralmente relevantes.

O primeiro requisito, (a), supra, pode ser combatido por meio do denominado argumento da sobreposição das espécies (species overlap), mais comumente conhecido como argumento dos casos marginais (marginal cases). Em resumo, este argumento sustenta que a atribuição de valor moral com base em capacidades, relações ou atributos supostamente caracterizadoras de um padrão humano, é uma estratégia equivocada pois, por diversas razões, sempre existirão indivíduos humanos que não as possuirão. O sentido fundamental para se compreender a "marginalidade" a que se refere o termo diz respeito a uma ausência, seja ela temporária ou definitiva, das capacidades ou critérios que, em termos 
comparativos, são supostamente caracterizadoras de um padrão daquilo tido por "normal" ou paradigmático para os seres humanos.

Naconecy expõe as consequências da sobreposição das espécies com clareza ao expor a seguinte linha de raciocínio:

(i) o interlocutor que é favorável à utilização de animais por parte dos humanos é convidado a dar uma justificativa para isso;

(ii) a razão dada será a de que os animais não têm determinada aptidão;

(iii) para qualquer aptidão citada, haverá alguns seres humanos que estão privados dela (os casos "marginais": pessoas com retardo mental grave, crianças recém-nascidas, idosos com demência senil avançada, bebês anencefálicos, doentes de Alzheimer, etc.);

(iv) portanto, o interlocutor deveria também ser favorável à utilização desses humanos pela mesma razão por ele apresentada;

(v) mas o interlocutor não concordaria com isso - o que mostra que ele é incoerente e preconceituoso (NACONECY, 2006, p. 162-163).

O argumento da sobreposição das espécies deixa, portanto, patente a incoerência da lógica da exclusão da comunidade moral de determinadas espécies por supostamente não possuírem determinadas características, atributos ou capacidades. Se não deixamos de proteger e tutelar seres humanos que carecem justamente dessas capacidades, não deveríamos deixar de proteger indivíduos pertencentes a outras espécies. Fundar a concessão de direitos fundamentais na posse desses atributos deixa os próprios seres humanos vulneráveis, pois, por diversas razões, sempre haverá humanos que, por alguma razão, deixarão de possui-los.

O segundo, requisito (b), supra, (para a validade da excepcionalidade humana, deveria ser demonstrado que somente os seres humanos detêm as capacidades apontadas como caracterizadoras como demarcadoras da comunidade moral) possui, também, um contraponto teórico consistente na comunhão biológica e evolutiva destas mesmas capacidades entre as espécies animais (argumento do contínuo das espécies).

Essencialmente, o reconhecimento da existência de um contínuo evolutivo entre as espécies prejudica a ideia de que haveria atributos únicos ou exclusivos. $\mathrm{Na}$ verdade, a comunidade científica reconhece que a maior parte dos animais compartilha evolutivamente desses mesmos atributos, com diferenças apenas de grau/intensidade e não de essência. A maior parte das habilidades e capacidades que os humanos possuem podem ser encontradas, em graus variados, em outros animais. 
Evelyn Pluhar, apresentando novamente, com outra roupagem mais genérica, o argumento da sobreposição das espécies, aponta que a consequência prática da comunhão de características moralmente relevantes é a de que:

(1) indivíduos que possuem uma mesma variedade de características moralmente relevantes são similarmente moralmente inerentemente valiosos;

(2) alguns animais não humanos possuem uma variedade de características moralmente relevantes que os seres humanos; $\mathrm{e}$

(3) diante disso, alguns animais não humanos e alguns humanos são similarmente inerentemente valiosos (PLUHAR, 1995, p. 65).

O fato é que a evolução das espécies aponta para o compartilhamento das capacidades tidas como moralmente relevantes para a inclusão na comunidade moral. Inteligência, linguagem (comunicação), cultura, consciência, e até mesmo o senso moral, por exemplo, não são, nesse sentido, atributos exclusivos da humanidade ${ }^{39}$.

O terceiro requisito (c), supra, exige que para haver diferenciação de tratamento entre indivíduos deve haver uma diferença de capacidade que seja moralmente relevante para o tratamento em questão. Evidentemente que a sofisticação cognitiva pode ser relevante para estabelecer diferenciações de tratamento. Em outras palavras, ser racional pode ser, em determinadas circunstâncias, um fator moralmente relevante para justificar a diferenciação de tratamento (e.g. os limites de interferência e cuidado para com um recém-nascido podem e devem ser distintos dos dispensados aos adultos).

A alternativa mais frequentemente apresentada pela Ética Animal ao critério da razão, reside na avaliação da vulnerabilidade à dor e ao prazer (SINGER, 2009) como o critério para a consideração moral. Estaria envolvida, portanto, em primeiro plano, a capacidade de o indivíduo ser prejudicado em seu bem-estar experimental (e.g. ao avaliarmos se estamos autorizados a submeter um coelho a um teste dermatológico que envolve colocar produtos químicos nos seus olhos não está em jogo diretamente a maior ou menor capacidade cognitiva do coelho, mas sim a lesão direta ao seu corpo, ao seu bem-estar e à sua liberdade).

O critério moralmente relevante que pode justificar diferenciação de tratamento reside na avaliação da capacidade que um determinado ente possui de ser beneficiado ou prejudicado, de sentir dor ou prazer. Afirma-se, nesse sentido, que os indivíduos ditos sencientes seriam justamente os capazes de possuir sensações relacionadas a perdas ou benefícios de ordem experimental (vulnerabilidade ao sofrimento). Por conta disto, a senciência é normalmente tomada como o critério

\footnotetext{
39 Sobre as implicações morais do darwinismo sugere-se a leitura da obra de James Rachels intitulada Created From Animals: The Moral Implications of Darwinism (Oxford University Press, 1990).
} 
objetivo que tornaria possível o ingresso na comunidade moral; seria um prérequisito para que alguém possa possuir interesses. O sofrimento seria um "mal moral" 40 ou estado mental desagradável ou aversivo (DEGRAZIA, 2014) que caracterizaria o interesse fundamental em não sofrer por parte daqueles que possuem essa capacidade.

A "vacina" oferecida pela Ética Animal consiste em apontar para a necessidade de revisão do nosso padrão relacional como os animais, combatendo as reais causas da pandemia. Animais não são objetos, instrumentos, coisas. Há, portanto, um erro moral relevante no fato de utilizarmos animais para fins alimentares. Esse erro moral está diretamente relacionado ao problema da pandemia do coronavírus, pois as suas causas, anteriormente apontadas, residem no consumo de animais. Há um duplo problema nesse caso. O primeiro deles é tratar os animais como objetos, havendo alternativas plenamente viáveis para sua substituição. O segundo são os reflexos desse abuso para com os próprios seres humanos. É muito provável que, mantido o padrão de criação e consumo de animais, domésticos e selvagens, muito provavelmente no futuro ocorrerão problemas muito semelhantes ao atual. Para combater as reais causas e os efeitos devastadores de infecções zoonóticas como a proveniente do coronavírus, deveríamos parar de matar e comer animais não humanos.

\section{CONSIDERAÇÕES FINAIS}

Conforme se procurou demonstrar, a investigação das reais causas da pandemia do coronavírus estão diretamente associadas ao consumo de animais não humanos. As infecções zoonóticas possuem um potencial devastador cada vez mais significativo não só em função do aumento em termos absolutos do número de animais criados, manejados e abatidos, como também pela degradação ambiental (com avanço descontrolado sobre as áreas cobertas por vegetação natural), mudanças climáticas e pela intensa mobilidade das pessoas.

É fundamental, urgente e necessário que seja aproveitada esta oportunidade para que esse padrão de instrumentalização e consumo de animais, domésticos ou selvagens, seja alterado drasticamente. A não ser assim, é muito provável que novos episódios de infecções similares a do coronavírus atinja a humanidade. Esse padrão já vem ocorrendo há algum tempo. Diversas outras doenças que se originam do contato e consumo de animais não humanos já atingiram a humanidade, todas elas com efeitos extremamente relevantes e contornos imprevisíveis.

\footnotetext{
40 "Uma pedra não tem interesses porque não sofre. Nenhum modo de atingi-la fará diferença para o seu bem-estar. A capacidade de sofrer e sentir prazer, entretanto, não é apenas necessária, mas também suficiente para que possamos assegurar que um ser possui interesses - no mínimo o interesse de não sofrer. Um camundongo, por exemplo, tem interesse em não ser chutado na estrada, pois, se isso acontecer, sofrerá" (SINGER, 2009, 13).
} 
A Ética Animal procura se apoiar no critério apontado da senciência, que consiste na capacidade de sentir dor e prazer, para conferir status moral aos animais. O sofrimento é, em princípio, intrinsecamente ruim para qualquer sujeito que possa sofrer. Os seres sencientes possuem o interesse em manter seu bem-estar experimental, possuem o interesse fundamental de não sofrer. Este interesse, baseado nesta capacidade, deveria ser protegido de forma similar a interesses semelhantes (de intensidade e importância equivalentes) titularizados por seres humanos. Causar sofrimento, dano e morte sem razões suficientemente fortes para tanto (sem uma causa justificante especial) consiste, portanto, em conduta moralmente condenável. Essa conclusão, que parece um tanto quanto simples, constitui poderoso argumento para que combatamos o tratamento abusivo a que muitos animais estão submetidos.

Assim é que a ideia segundo a qual estamos autorizados a instrumentalizar e explorar outras espécies sencientes não se sustenta eticamente. Para que sejam combatidas as reais causas da presente pandemia dever-se-ia interromper a criação, morte e o consumo de animais não humanos.

Ao longo da história, não só seres humanos foram vitimados por epidemias. Animais também. Na gripe aviária, na gripe suína, no SARS-CoV-1, por exemplo, animais foram mortos aos milhões a fim de manter a humanidade protegida. Epidemias entre animais, com transmissão para humanos, no contexto da intervenção humana para a exploração de animais. É muito lamentável admitir que, após estes meses tão afetados pela pandemia, o comportamento humano diante dos animais não tenha tido alteração substancial. E nem mesmo maior discussão a respeito. Muitas vezes a questão quando levantada diz apenas quanto à higiene: possibilitar mercados limpos. Para, assim, seguir capturando, prendendo, matando e consumindo os corpos de animais. Sem risco para seres humanos, isto é, sem problema.

Para aqueles que procuram a causa da pandemia, antes de elucubrações esotéricas ou apocalípticas, antes de cogitar de uma vingança da natureza ou dos animais contra a humanidade, é melhor reconhecer que ela está na própria conduta humana, na insensibilidade, na falta de compaixão, na negação do outro, no especismo, na arrogância, na brutalidade, na rejeição de que animais têm interesses e direitos e que tais direitos, os mais básicos, (a integridade física e psicológica, a liberdade, a vida) estão sendo cotidianamente violados por seres humanos, pela maioria da espécie humana. E isto não apenas ou sobretudo para evitar uma próxima pandemia, mas sim para diminuir o sofrimento e o mal que há neste mundo e que, em boa medida, são frutos da ação humana, contra os próprios membros da sua espécie e contra animais.

\section{REFERÊNCIAS}


ANDERSEN, K.G., RAUMBAUT, A., LIPKIN, W.I. et al. The Proximal Origin of SARS-CoV-2. Nat Med 26, 450-452 (2020).

Åsjö B.; Kruse H. Zoonoses in the Emergence of Human Viral Diseases. Perspect Med Virol. 2006, p.15-41. doi:10.1016/S0168-7069(06)16003-6.

CYRANOSKI, David. Mystery Deepens Over Animal Source ff Coronavirus. Pangolins Are a Prime Suspect, but a Slew of Genetic Analyses Has Yet to Find Conclusive Proof. In: https://www.nature.com/articles/d41586-020-00548w?fbclid=IwAR1TaU8leMGzeMUzV0uZVIOBskJC2Zh4P7hixJfBEvwnsouHZGZn F4QTz_A.

DEGRAZIA, David. Taking Animals Seriously: Mental Life and Moral Status, Cambridge, Cambridge University Press, 1996.

DIKÖTTER, Frank. A Grande Fome de Mao: a história da catástrofe mais devastadora da China - 1958-62. Tradução por Ana Maria Mandim. Rio de Janeiro, São Paulo: Record, 2017.

GAO F. ; BAILES E., ROBERTSON D.L., et al. Origin of HIV-1 in the chimpanzee Pan troglodytes troglodytes. Nature. 1999;397(6718):436-441. doi:10.1038/17130.

GODLOVITCH, Stanley; HARRIS, John. Animals, Men and Morals: An Inquiry into the Maltreatment of Non-Humans. London: Grove Press, 1971.

HORTA, Oscar. The Scope of the Argument from Species Overlap, Journal of Applied Philosophy, v. 31, n. 2, 2014, pp. 142-154.

Kangpeng Xiao, Junqiong Zhai, Yaoyu Feng, Niu Zhou, Xu Zhang, JieJian Zou, N a Li, Yaqiong Guo, Xiaobing Li, Xuejuan Shen, Zhipeng Zhang, Fanfan Shu, Wany i Huang, Yu Li, Ziding Zhang, Rui-Ai Chen, Ya-Jiang Wu, Shi-

Ming Peng, Mian Huang, Wei-Jun Xie, Qin-Hui Cai, Fang Hui Hou, Yahong Liu, Wu Chen, Lihua Xiao, Yongyi Shen. Isolation and Characterization of 2019-nCoV-like Coronavirus from Malayan Pangolins. BioRxiv (The Preprint Server for Biology) 2020.02.17.951335. Disponível em: https://www.biorxiv.org/content/10.1101/2020.02.17.951335v1 Acesso em 4 out. 2020.

LI X, Zai J, Zhao Q, et al. Evolutionary history, potential intermediate animal host, and cross-species analyses of SARS-CoV-2. J Med Virol. 2020; 92:602-611. 
LOURENÇO, Daniel Braga. Fronteiras da inclusão: implicações éticas do contínuo das espécies. In: Ética Aplicada: Animais. Orgs. NEVES, Maria do Céu Patrão; ARAUUJO, Fernando. Lisboa: Almedina, 2018.

NACONECY, Carlos M. Ética \& Animais: Um Guia de Argumentação Filosófica, Porto Alegre, EDIPUCRS, 2006.

PAIM, Cynthia Schuck Paim; ALONSO, Wladimir J. Pandemias, saúde global e escolhas pessoais. Alfenas: Cria Editora, 2020.

PLUHAR, Evelyn. Beyond Prejudice: The Moral Significance of Human and Nonhuman Animals. London, Duke University Press, 1995.

SINGER, Peter. Libertação Animal. São Paulo: Martins Fontes, 2009.

Taubenberger J.K.; Morens D.M.; 1918 influenza: the mother of all pandemics. Emerg Infect Dis, v. 12, n. 6, 2006, p. 15-22.

WHO/FAO. Second Report of the Joint WHO/FAO Expert Committee on

Zoonoses. WHO Technical Report Series, n. 169. Geneva: WHO; 1959. Disponível em:

<https://apps.who.int/iris/bitstream/handle/10665/40435/WHO_TRS_169.pdf?sequ ence=1\&isAllowed=y Acesso em: 20 jul 2020.

UJVARI, Stefan C. A História da Humanidade Contada pelos Vírus, Bactérias, Parasitas e outros Microrganismos. São Paulo: Contexto, 2019. 